Fukushima J. Med. Sci.,

Vol. 58, No. 1, 2012

\title{
[Commentary]
}

\section{PITFALLS AND PRACTICALITIES IN COLLECTING AND BANKING HUMAN BRAIN TISSUES FOR RESEARCH ON PSYCHIATRIC AND NEULOGICAL DISORDERS}

\author{
RIVKA RAVID ${ }^{1)}$ and KEIKO IKEMOTO ${ }^{2,3)}$ \\ ${ }^{1)}$ Netherlands Institute of Neurosciences, Meibergdreef 47 BA Amsterdam, the Netherlands, ${ }^{2)}$ Department \\ of Neuropsychiatry, Fukushima Medical University, School of Medicine, 1 Hikarigaoka, Fukushima, \\ 960-1295, Japan, ${ }^{3}$ Department of Psychiatry, Iwaki Kyoritsu General Hospital, 16 Kusehara, Mimaya- \\ machi, Uchigo, Iwaki, Fukushima, 973-8555, Japan
}

(Received June 13, 2011, accepted February 28, 2012)

\begin{abstract}
It is essential to examine brain materials for the understanding the cause and pathology of mental disorders. Recent methodological progress urges us to set up well qualified brain banks. Human tissue and Bio-banking is a complex field and the daily practice of brain banks needs to abide by several golden standards in order to avoid pitfalls in basic research : 1) A donor system in which informed consent is granted for the use of the samples for scientific research, including genetic analysis and access to medical records, 2) Rapid autopsy system, 3) Compatibility of protocols for procurement, management, handling and storage, 4) A generally accepted consensus on diagnostic criteria, 5) Quality control, 6) Abiding by local/international legal and ethical guidelines for work with human material, 7) Proper safety procedures. In the present review, the authors introduced the activities of European brain banks, and discussed on their current issues, and on the problems remain to be resolved.
\end{abstract}

Key words : brain bank, post-mortem brain, research resource, European brain bank network, quality control

\section{INTRODUCTION}

The growing number of techniques applicable on post-mortem samples increases the pressure from the scientific community and the pharma companies on brain banks to supply growing numbers of autopsy material from brain donors who suffered from a psychiatric disorder. Most active brain banks have been established in the past decades and form at present an important bridge between donors, their relatives, clinicians, neuropathologists, scientists and the pharma and bio industry, who is looking for targets and developing drugs (Figure 1).

The specimens used for research should be obtained from donors who had a psychiatric disease and matched non-disease control cases. Quality control and matching the samples is essential to cor- rect for the enormous variability in patient material; These include age, gender, clinical history, medication prior to death, agonal state $/ \mathrm{pH}$, seasonal and annual variation, post mortem-delay, handling methods, fixation time and storage time ${ }^{1,2)}$. The diagnosis of psychiatric diseases is severely hampered by the absence of suitable biomarkers that can be measured in body fluids such as blood and cerebrospinal fluid (CSF). These markers can explain the pathological mechanisms underlying the various diseases and have a predictive value in early diagnostics and should be collected as well when possible.

\section{BACKGROUND}

The possible causes and underlying pathologies

RIVKA RAVID，池本桂子

Corresponding author : Keiko Ikemoto E-mail address : ikemoto@fmu.ac.jp ; ikemoto@iwaki-kyoritsu.iwaki.fukushima.jp https://www.jstage.jst.go.jp/browse/fms http:/www.fmu.ac.jp/home/lib/F-igaku/ 
of most psychiatric disorders are still unknown and current scientific research is focusing on the neurobiological entities and the possible changes occurring in the brains of affected patients. The European brain banks collecting specimens of psychiatric cases are fairly young ; there is no standard protocol for collection and handling of tissues and the consensus for the diagnostic criteria is still incomplete ${ }^{1,3-6)}$. In order to be able to closely follow and continuously update techniques, protocols and diagnostic procedures, brain banks need to be in the immediate proximity of an academic center with a strong neuroscience tradition. The brain banks also need to establish a well functioning donor program and have an ongoing collaboration with a large number of patient's associations, clinicians, hospitals, mental institutions, nursing homes, pathologists, undertakers, autopsy assistants and scientists.

All cases in the disease groups and controls should be well matched for various factors, both ante-mortem and post-mortem. Ante-mortem factors include age, sex, agonal state, seasonal alterations, circadian variation, clock time of death and medication. Post-mortem factors include postmortem delay, fixation and storage time and laterality $^{7-12)}$

The availability of post-mortem material from patients with psychiatric disorders is still limited while the interest from the international scientific community is ever-growing. In order to provide a solution to this problem, collaboration with psychiatric departments and institutions is important to implement a post-mortem research programme for depression, bipolar disorders and schizophrenia, including the possibility of genetic research through simultaneously approaching patients and their relatives. The psychiatrist approaches the potential candidates and conducts the ante-mortem and retrospective diagnostics ${ }^{13)}$.

Post-mortem research of schizophrenia did not progress rapidly partly due to the development of several techniques which enabled scientists to do in-vivo research on patients by applying computerized tomography (CT) and Magnetic Resonance Imaging (MRI) which proved to be successful, noninvasive and fast techniques to investigate the morphology of the brain. The development of neuroleptica and the lack of clear histopathological markers for the disease as well as a lack of consistent findings from the neuropathological studies contributed to the loss of interest in post-mortem research. Several structural imaging studies showed subtle changes in the brain structure, for example enlargement of the ventricles and the cortical sulci as well as smaller hippocampi. This implies a neurobiological substrate for schizophrenia. Minor tissue abnormalities were also reported in limbic structures and limbic dysfunction may lead to a dissociation between cognitive activities and basic emotional reactions which may account for several aspects of the psychopathology of the disease.

MRI studies revealed a decrease in the size of the thalamus in schizophrenia which may in turn account for hallucinations and delusions ${ }^{14)}$. Postmortem studies of the thalamus indicated a reduction of neurons in the mediodorsal nucleus (MDN) as well as a volume reduction of $\mathrm{MDN}^{15}$. Other findings such as cortical asymmetry indicated that schizophrenia is a disorder in the early neurodevelopmental stage of brain growth, an argument against the notion of the disease being a degenerative brain disorder ${ }^{16,17)}$.

The interest in post-mortem research increased in the last decade due to the applicability of various modern neurobiological techniques on post-mortem material. Immunocytochemistry, in situ hybridization, receptor autoradiography and DNA-micro arrays/chip techniques are all leading to a better understanding of disease processes ${ }^{18,19)}$.

Recent in vivo research shows indications for the existence of comparative abnormalities in the cerebral morphology of family members of schizophrenia patients, as in healthy siblings. These points towards a possible hereditary factor which plays an important part in the genetics and/or development of the morphological abnormalities. Postmortem research on autopsy material creates the possibility of investigation of a possible hereditary base through changes in gene expression in the different brain structures in patients, family members and controls.

Several gene profiling techniques are used at present to search for differential gene expression on anatomically well defined subdivisions of the thalamus and cortex in specimens of controls and schizophrenic patients. In this manner insight may be gained in the underlying mechanisms of the abnormalities found with the in-vivo techniques, and possibly in the pathogenesis of schizophrenia. As there is no generally accepted animal model for schizophrenia regarding anatomical changes, post-mortem research will require human cerebral tissue.

Brain banks have been set up in many European countries in order to support research on psychiatric disorders. Through close collaboration between 
banks and a large number of research groups in Europe, the individual efforts are intensified and the total effect is maximized. Human tissue and Biobanking is a complex field and the daily practice of Brain Banks needs to abide by several golden standards in order to avoid pitfalls in basic research :

1. A donor system in which informed consent is granted for the use of the samples for scientific research, including genetic analysis and access to medical records.

2. Rapid autopsy system

3. Compatibility of protocols for procurement, management, handling and storage

4. A generally accepted consensus on diagnostic criteria

5. Quality control

6. Abiding by local/international legal and ethical guidelines for work with human material

7. Proper safety procedures

\section{ORGANIZATION AND AIMS OF THE EUROPEAN BRAIN BANKS}

a. The main task is to foster research in clinical and basic neuroscience and serve as a dynamic system with ongoing consultations on the many various daily issues of brain banking. The banks support the exchange of control cases on European level. Finding the suitable and sufficient numbers of controls is one of the most difficult objectives of every brain bank. The optimal strategy is to try to get the spouse of the donor to sign up as a control. The brain bank has to try to get exact clinical records of all patients, preferably soon after the patient signed up as a donor. The cause of death and time of death must be known and registered. Clinical data from patients who suffered from a psychiatric disorder should be obtained in a standardized way conform the internationally accepted clinical criteria.

The agonal state of the patient must be assessed pre-mortem and the agonal state of the tissue must be assessed post-mortem by measuring the $\mathrm{pH}$ of the ventricular CSF obtained at autopsy $y^{7,20,21)}$.

b. Achieve standardization between banks of commonly accepted criteria for the neuropathological diagnosis and compatibility of protocols for tissue procurement, management and preparation. Over the past 15 years, several European meetings aiming at standardization of diagnostic and preparative protocols and to enhance collaborative post mortem brain research have been organized. A persistent issue has been whether there is a need for a single central European bank. The consensus view is that this would be neither efficient nor feasible, as the effectiveness of tissue banking is very much driven by local motivation ${ }^{22)}$. The enormous variability in methods within the Europaean brain banking community has been demonstrated by various concordance studies and concerted actions supported by the European Community.

c. The European brain banks network has to facilitate multi-center concordance studies and studies of risk factors in psychiatric diseases which have genetic end environmental components. These factors play an important role in psychiatric diseases, but their exact role in schizophrenia and affective disorders is still quite vague. Studies performed on a European basis will enable screening a larger number of well documented cases. Furthermore, the genetic basis can be investigated in populations that are known to be susceptible in different degrees. Most brain banks started collecting DNA samples and the isolation and storage of DNA is essential for future research ; this can be done from both frozen and fixed tissues.

d. Safety measures - all European brain banks collect a broad variety of cases and store frozen and fixed specimens. Possible infectivity is a substantial problem, especially in respect to HIV and prion diseases. Secure storage is important and needs to take into account each specimen as possibly hazardous ${ }^{23,24)}$. The safety procedures must abide by established international guidelines. The staff should be immunized against Hepatitis B and strictly follow the procedures for safe handling.

e. Ethical and legal issues - ethical codes of conduct of the Brain Banks, the laws regulating autopsy procedures, and many other important relevant issues are significantly different in the various brain banks of the member states of the European Union $^{25)}$.

From an ethical point of view, European Brain Banks take the following aspects into consideration in their daily practice ${ }^{26,27)}$ :

Tissue procurement: includes all factors related to the donor programme. Written consent of the donor and/of next-of-kin at time of death or earlier. This is mandatory for use of tissues for medical and basic research. Respect for the dignity of human remains is considered at all times. All staff working with human remains are properly trained and qualified.

Tissue management : includes factors related to collection, handling and preservation of tis- 
sues. All human tissues should be regarded as potentially biohazardous and should be handled accordingly by appropriately trained personnel. Specific precautions should be taken against known hazards and general precautions against unknown hazards. All clinical documentation and information concerning the tissues should be made available to users as quickly as possible. All those potentially exposed to human brain tissues and fluids should be vaccinated against hepatitis- $B$ virus and be regularly checked for level of immunity. All disposable equipment used in conjunction with human brain tissues and fluids should be sterilized according to a recommended procedure before transport for incineration.

Tissue dissemination : factors related to scientific research and supplying samples of high scientific quality and properly matched for specific projects. Users of the brain samples should undergo a process of accreditation, to ensure that a minimum set of criteria is fulfilled. These criteria include safe tissues, scientific reputation, ethical credibility, proper training, suitable facilities for safe handling and disposal of human tissues and confidentiality. Whenever possible, this accreditation should be performed by an appropriately qualified and independent expert group. As the legislation and documentation concerning shipment of human autopsy specimens varies between the European countries, the information regarding regulations of packing and national and international transport of human brain tissues and fluids should be made available to all parties involved in brain bank activities for research.

Confidentiality : the anonymity of tissues and patient records must be protected at all times. Samples supplied for research should be coded by the Brain Bank and a tissue tracking system restricted to local Brain Banks must be established to guarantee the anonymity of the donor.

Research using human tissues can bring new information about the donor which is also relevant to his family. This option should play an important role in the ethical conduct. The acquired confidence with the donor may become irrelevant and the possibility of giving information about new findings should be taken into account.

"Financial gain": from a legal and ethical point of view it is highly important to establish brain banks as nonprofit sources of human tissues for scientific research. The brain banks act as a custodian of brain tissue and the tissues must not be commercially handled. On the other hand, it is extremely important to have a reasonable coverage for the costs involved in procurement, handling and transport. All technical and scientific activities and expenses related to handling and management of tissues as well as the costs involved in the acquisition and/or preservation of the tissues can be considered as a budget to be paid when tissues are requested for research. The various professionals who are involved in obtaining, handling and diagnosing the tissues have the right to be reimbursed for their services. It must be made clear in writing to all users that any possible payments are only made to cover the costs of Brain Banks that are forbidden to make any financial profit.

Genetic testing: the tremendous advances in genetic research in our decade raise serious ethical problems and complexities; there is sometimes conflicting interest in the need for knowledge and information on the one hand and the use and implications of this information for the people involved. The link found between certain genes and neurological diseases, creates a heavy burden on physicians, health care workers and brain bankers who test for these genetic factors as they are essential for the diagnostics and scientific interpretation of the results obtained on post-mortem human brain tissues and fluids. This knowledge poses many difficult questions to concerned or afflicted individuals.

The rapid linkage between genes and diseases will have many future implications on the international legal and ethical systems. It would be advisable to have a consensus between European brain banks on that issue, as some of the genetic testing is done by collaboration between experts in different member countries of the EC.

When working in the framework of the European community, each Brain Bank should be well aware of the current international discussions being considered with respect to ownership and use of post-mortem tissues for scientific research. In practice, when necessary, changes to the legal frameworks operating in the various European countries are sought in conjunction with the relevant authorities, in order to facilitate the procurement of human tissues and its supply in a suitable form to end-users.

A European network of tissue banks is legally and ethically the optimal approach to the procurement and distribution of tissue for scientific res$\operatorname{earch}^{28)}$. This in turn will ensure the progression towards understanding of the mechanisms of the various psychiatric disorders and will advance and enhance the development of appropriate therapeutic strategies. All European Brain banks abide by the 
national legal and ethical requirements and respect the principles expressed in the Helsinki Declaration, the conventions of the Council of Europe on human rights and biomedicine, and the UNESCO Declaration on the human genome.

Investigating the biological basis of psychiatric diseases requires a professional battery of techniques applied by brain banks. The dissection, handling, storage and dissemination of samples should be much better co-ordinated among the various European brain banks.

Since the various European brain banks do not use identical protocols for tissue acquisition, dissection and storage, they will have to look for a final common pathway to increase the efficiency of postmortem research. One such possible pathway would be development of compatibility of procedures and protocols for the various collections. Future research will apply among others genomics, proteomics and morphometry as possible methodologies; supplying clinically and neuropathologically well documented material by European brain banks can significantly contribute to the understanding of the causes and pathologies of the various disorders and may soon lead to new targets for therapeutic agents.

\section{ACKNOWLEDGMENTS}

The author gratefully acknowledges the work of Dr. W. Kamphorst, Institute of Pathology, VUMC Amsterdam, The Netherlands.

\section{REFERENCES}

1. Ferrer I, Armstrong J, Capellari S, Parchi P, Arzberger T, Bell J, Budka H, Ströbel T, Giaccone G, Rossi G, Bogdanovich N, Fakai P, Schmitt A, Riederer P, Al-Sarraj S, Ravid R, Kretzschmar H Effects of formalin fixation, paraffin embedding, and time of storage on DNA preservation in brain tissue: A BrainNet Europe study. Brain Pathology, 17 : 297-303, 2007. [Epub Apr 23 2007]

2. Perry EK, Perry RH, Tomlinson BE. The influence of agonal state on some neurochemical activities of postmortem human brain tissue. Neurosi Lett, 29 : 303-309, 1982.

3. Cruz-Sánchez FF, Ravid R, Cuzner ML. The European Brain Bank Network (EBBN) and the need of standardized neuropathological criteria for brain tissue cataloguing. In : Cruz-Sánchez FF, Cuzner ML, Ravid R, eds. Neuropathological Diagnostic Criteria for Brain Banking, European Union Biomedical and Health Research, Vol. 10.
IOS Press, Amsterdam, The Netherlands, 1-3, 1995.

4. Ravid R. Standard operating procedures, ethical and legal regulations in BTB (brain/tissue/bio) banking: what is still missing? Cell Tissue Bank, Nov 6, 2007 : online [Epub ahead of print]

5. Schmitt A, Bauer M, Heinsen H, Feiden W: Consortium of Brainnet Europe II, Falkai P, Alafuzoff I, Arzberger T, Al-Sarraj S, Bell JE, Bogdanovic N, Brück W, Budka H, Ferrer I, Giaccone G, Kovacs GG, Meyronet D, Palkovits M, Parchi P, Patsouris E, Ravid R, Reynolds R, Riederer P, Roggendorf W, Schwalber A, Seilhean D, Kretzschmar. How a neuropsychiatric brain bank should be run : a consensus paper of Brainnet Europe II. J Neural Transm, 114 : 527-537, 2007. Epub 2006 Dec 14.

6. Johnston NL, Cervenak J, Shore AD, Torrey EF, Yolken RH, Cerevnak J. The Stanely Neuropathology Consortium. Multivariate analysis of RNA levels from postmortem human brains as measured by three different methods of RT-PCR. J Neurosci Meth, 77 : 83-92, 1997.

7. Ravid R, van Zwieten EJ, Swaab DF. Brain Banking and the human hypothalamus-factors to match for, pitfalls and potentials. In : Swaab DF, Hofman MA, Mirmiran M, et al., eds. The human hypothalamus in health and disease. Elsevier, Amsterdam, Progress in Brain Res, 93 : 83-95, 1992.

8. Ravid R, Swaab, DF. The Netherlands Brain Bank; a clinico-pathological link in aging and dementia research. J Neural Transm, Suppl. 39 : 143-153, 1993 Springer-Verlag, Vienna, Austria.

9. Ravid R, Winblad B. In : Corain B, Iqbal K, Nicolini M, Winblad B, Wisniewski H, Zatta P, eds. Alzheimer's Disease : Advances in Clinical and Basic Research, John Wiley \& Sons, Sussex, U.K., 213-218, 1993.

10. Ravid R, Swaab DF. Brain Banking in Alzheimer's disease: pitfalls and potentials. J Neuropath Appl Neurobiol, Vol. 21, Suppl. 1: 18-19, 1995a.

11. Ravid R, Swaab DF, Kamphorst W, Van Zwieten EJ. A golden standard protocol for the brain banking society? The Amsterdam Experience. J Neuropathol Exp Neurol, Vol. 54, Supplement, 25-26S, 1995b.

12. Ravid R, Swaab DF, Van Zwieten EJ, Salehi A. Controls are what makes a brain bank go round. In : Cruz-Sanchez FF, Ravid R, Cuzner ML, eds. Neuropathological Diagnostic criteria for Brain Banking. IOS Press, Amsterdam, 4-13, 1995c.

13. Riederer P, Gsell W, Calza L, Franzek E, Junkunz G, 
Jellinger K, Reynods, GP, Crow T, Cruz-Sanchez FF, Beckmann H. Consensus on minimal criteria of clinical and neuropathological diagnosis of schizophrenia and affective disorders for post-mortem research. J Neural Transm, 102 : 255-264, 1995.

14. Andreasen NC, Arndt S, Swayze V II, Cizadlo T, Falum M, O’Leary D, Ehrhardt JC, Yuh, WTC. Thalamic abnormalities in schizophrenia visualized through magnetic resonance image averaging. Science, 266 : 294-298, 1994.

15. Pakkenberg B. Pronounced reduction of total neuron number in mediodorsal thalamic nucleus and nucleus accumbens in schzophrenics. Arch Gen Psychiatry, 47 : 1023-1028, 1990.

16. Bogerts B. Recent advances in the neuropathology of schizophrenia. Schizopht Bull, 19 : 431445, 1993.

17. Bogerts B. The neuropathology of schizophrenic disease: historical aspects and present knowledge. Eur Arch Psychiatry Clin Neurosci, 249, Supll 4 : 2-13, 1999.

18. Kahn J, Bittner ML, Chen Y, Meltzer PS, Trent JM. DNA microarray technology ; the anticipated impact on the study of human disease. Biochem Biophys Acta 1423 : M17-M28, 1999.

19. Orr S, Alexandre E, Clark BJ, Gray N, Helin H, Ravid R, Read M, Richert L, Roosipuu R, JonssonRylander AC, Syring C, Teesalu T, Thasler WE, Trafford J, Van Der Valk J, Weiss TS, Womack C, Ylikomi T. Fourth meeting of the European Network of Research Tissue Banks - Future strategy to increase collaborations in the supply of human tissue for biomedical research. Cell Tissue Bank, 6 : 131-138, 2005.

20. Hardy JA, Wester P, Winblad B, Gezelius C, Bring G, Eriksson A. The patients dying after long terminal phase have acidotic brains ; implications for biochemical measurements on autopsy tissue. J Neural Transm, 61 : 253-264, 1985.

21. Kingsbury AE, Foster OJ, Nisbet AP, Cairns NJ, Bray L, Eve DJ. Tissue $\mathrm{pH}$ as indicator of mRNA preservation in human post-mortem brain. Brain Res Mol Brain Res, 28 : 311-318, 1995.

22. Duyckaerts C, Delaère P, Hauw JJ, Abbamondi-
Pinto AL, Sorbi S, Allen I, Brion JP, FlamentDurand J, Duchen L, Kauss J, Schlote W, Lowe J, Probst A, Ravid R, Swaab DF, Renkawek K, Tomlinson B. Rating of the lesions in senile dementia of the Alzheimer type: concordance between laboratories. A European multicenter study under the auspices of EURAGE. J Neurol Sci, 97 : 295-323, 1990.

23. Bell J, Ironside J. Principles and practice of "high risk" brain banking. Neuropathol Appl Neurobiol, 23 : 281-288, 1997.

24. Hauw, JJ, Sazdovitch V, Maokhtari K, Seilhaen D, Camilleri S, Kondo H, Duyckaerts C. Techniques de prevention des agents trasmissibles non conventionnels au laboratoire. Lexemple de l'anatomie pathologique. In : Grosset J, Kitzis $\mathrm{M}$, Lambert N, Sinegre M, eds. Prevention des infections nosocomiales. Protection contre les germes multiresistants, Paris, Arnette Blackwell, 171-177, 1995.

25. Cruz-Sánchez FF, Mordini E, Ravid R. Ethical aspects to be considered in brain banking. Ann Ist Super Sanità, 33 : 477-482, 1997.

26. Bidaut-Russell M, Ravid R, Cruz-Sánchez FF, Grossberg GT, McKeel DW. Survey of North American and European dementia brain banks : a 1994 directory. Alzheimer's disease and Related Disorders, 9 : 193-202, 1995.

27. Ravid R. Methodological considerations of the establishment of a Brain Bank for psychiatric research ; The Amsterdam and European experience. In : Agam G, Belmaker RH, Everall I, eds. The Post-Mortem Brain in Psychiatric Research, Kluwer Academic Publishers, Massacchusettes, USA, 2002.

28. Anderson R, Balls M, Burke MD, Cummins M, Fehily D, Gray N, de MG, Helin H, Hunt C, Jones D, Price D, Richert L, Ravid R, Shute D, Sladowski D, Stone H, Thasler W, Trafford J, van der Valk J, Weiss T, Womack C, Ylikomi T. The establishment of human research tissue banking in the UK and several western european countries: the report and recommendations of ecvam workshop 44. Altern Lab Anim, 29 : 125-134, 2001. 